\title{
Examining Enterprise Resource Planning Post Implementation and Employees' Performance in Small and Medium Enterprises Using DeLone and McLean's Information System Success Model
}

\author{
Erlane K Ghani ${ }^{1}$, Siti Aimi Mohamad Yasin ${ }^{1} \&$ Mazurina Mohd Ali $^{1}$ \\ ${ }^{1}$ Faculty of Accountancy, Universiti Teknologi MARA, Malaysia \\ Correspondence: Erlane K Ghani, Faculty of Accountancy, Universiti Teknologi MARA, Malaysia.
}

Received: April 20, 2019

Accepted: May 7, 2019

Online Published: May 19, 2019

doi:10.5430/ijfr.v10n3p153

URL: https://doi.org/10.5430/ijfr.v10n3p153

\begin{abstract}
This study examines the effect of Enterprise Resource Planning (ERP) post implementation on employees' performance in Small Medium Enterprises (SME) in Malaysia. Specifically, this study relies on the DeLone and McLean's information system success model that proposes three quality dimensions namely, system quality, information quality and service quality in examining the effect of ERP post implementation on employees' performance in SMEs. Using a questionnaire survey on 117 respondents that have experience in ERP, this study shows that out of the three qualities of ERP, system quality and service quality have a significant positive effect on employees' performance in the SMEs. This study shows that information quality does not have a significant effect on employees' performance in Malaysia. This study contributes to the information system literature and provides information regarding the quality dimensions which could help managers or ERP providers to assess the success of their ERP implementation.
\end{abstract}

Keywords: enterprise resource planning, system quality, information quality, service quality, employees' performance

\section{Introduction}

As a result of globalisation and advancement in technology, the business environment is constantly changing and has become increasingly complex with functional units. There is also a need for greater interaction between businesses and their customers. Businesses need to have integrated functional units that require inter-functional information flow for decision making, efficient procurement, inventory management, accounting, human resources and distribution of goods and services (Sahran, Goni \& Mukhtar, 2010). In addition, businesses are also facing the challenges of increased competition and customers' expectation and also, business expansion due to the complexity of the business environment. One of the ways to overcome these challenges is by implementing Enterprise Resource Planning (ERP).

ERP is recognised as a system that provides an essential platform for businesses to build their competitive business process upgrades and increase competitive advantage (Caruso, 2003; Botta-Genoulaz \& Millet, 2006). The utilisation of ERP previously, has been mostly exclusively attributed to large businesses due to their size, nature and complexity. However, ERP implementation among Small and Medium Enterprises (SMEs) either in developed or developing countries has become common due to the technology becoming more advanced, with lower implementation cost (Ahmad \& Cuenca, 2013). This is evidenced by the increasing number of ERP vendors which have targeted the SMEs, and that many large ERP vendors such as SAP and Microsoft are actively expanding their activities to the SME sector with repackaged ERP systems (Pinedo-Cuenca, Shaw, Ahmad \& Abbas, 2004). ERP requires a greater degree of coordination and complex technological infrastructure within a business. Therefore, ERP vendors would provide this system by considering the SMEs' budget and time constraints and present economical, simple, easy-to-install, pre-configured ERP systems or hosting services (Venkatraman \& Fahd, 2016).

The high number of SMEs in Malaysia proved that the SMEs play an essential role in the country's economy and are profitability (Idrus \& Shahawai, 2009). The SMEs are categorised into three levels which are (1) Micro-enterprise, (2) Small enterprise and (3) Medium enterprise. There are two key elements used to define a SME namely, (1) Annual Sale Turnover and (2) Number of Full-Time Employees (SME Annual Report 2016/17). SMEs are involved in all 
types of industry, considering that they have diversity in their range and significance (Idrus \& Shahawai, 2009). However, they are highly concentrated in the services sector, which accounted for $89.2 \%$ (809,126 firms) of total SME establishments. Meanwhile, about 5.3\% of SMEs $(47,698)$ are involved in the manufacturing sector, followed by $4.3 \%(39,158)$ in the construction sector, $1.1 \%(10,218)$ in the agriculture sector with the remaining $0.1 \%(865)$ in the mining \& quarrying sector. The Minister in the Prime Minister's Department, Datuk Seri Dr Wee Ka Siong has recently noted "In the recent period between 2011 and 2015, SME grew at an average annual rate of 6.7\%, outperforming the overall average growth of the economy of 5.3\%. Currently, 97\% of the business establishments in Malaysia are SMEs" (Lee, 2017). Arguably, SMEs would involve high information and communication technology usage and business process.

The growth of ERP implementation among SMEs across various industries indicates that the SMEs are aware of the benefits of ERP that enable them to integrate the information pertaining to all business processes into one system and to have greater interaction between their customers and suppliers which are carried out electronically (Caruso, 2003; Gyebi,Owusu \& Etroo 2013). At present, many medium to large businesses are already in the post implementation phase, indicating their experience and implementation of ERP of at least one cycle of ERP (Brehm, Heinzl \& Markus, 2001). However, despite the huge investment in ERP implementation, the benefits of ERP post implementation are not guaranteed (ERP Report, 2015). Many businesses have realised that the ERP implementation has not always been successful (He, 2004; Sun, Yazdani, \& Overend, 2005; Wang, Shih, Jiang, \& Klein, 2008). Yu (2005) noted that a number of studies have evidenced that the expected benefits cannot be easily obtained from the ERP during the post implementation stage. A recent survey found that 65 percent of businesses have suffered operation stoppages after ERP post implementation phase and 53 percent of businesses have failed to realise half of their projected benefits (ERP Report, 2015). Therefore, the ERP post-implementation phase is considered as a critical phase. However, research on this phase has yet to be explored thoroughly.

This study aims to extend the current information system (IS) literature by revisiting DeLone and McLean's information system (IS) success model $(1992,2003)$. Specifically, this study examines the effect of system quality, information quality and service quality in examining the effect of ERP on employees' performance in the SMEs. The remainder of this paper is structured as follows. The next section provides a review of relevant literature. Section 3 presents the research framework and research hypotheses underpinning this study and section 4 outlines the research design. The results are presented in section 5. The last section, section 6 summarises and concludes this study.

\section{Literature Review}

\subsection{Individual Performance}

Individual performance such as employees is described as a set of realisation of benefits (Armstrong \& Baron, 2002; Sonnentag \& Frese, 2003; Gumusgul, 2018). Performance can be measured by looking at several aspects such as speed, time, accuracy, efficiency and effectiveness (Bailey \& Pearson, 1983; Ford \& Gelderblom, 2003). It is important that a system can provide people with useful information so that they can work and make decisions (Spool, Scanlon, Schroeder, Snyder \& Deangelo, 1999). This success is measured in terms of speed and accuracy of obtaining the necessary information to users from a system to complete their tasks. In addition, performance can be evaluated using two performance measurement approaches namely productivity and quality of work. According to Hodgkinson (1999), performance is often measured using quantitative and qualitative indicators, which are classified into three main indicators of effectiveness, efficiency and quality in order to determine the relationship between the input and output of resources. Besides, creativity can also be an indicator of performance measurement which refers to the ability of people to create new ideas related to their work.

Studies have suggested that individual performance can be influenced by many factors that lead to differences in performance. According to Sonnentag and Frese (2003, p.8), individual performance refers to the "Differences in performance between individuals can be explained by individual differences in abilities, personality and/or motivation". For example: Rajan and Baral (2015) investigated the effect of individual, organisational, and technological factors: computer self-efficacy, organisational support, training, and compatibility on an IS usage and its impact on the end user. They found that computer self-efficacy, organisational support, training, and compatibility have a positive influence on the information system usage which in turn had significant impact on the end users' panoptic empowerment and individual performance. Another factor that can influence individual performance is ERP.

\subsection{Enterprise Resource Planning (ERP)}

Previous studies have provided many definitions of ERP. In general, the definitions are related with the term 
"integration". ERP is defined as a software package that integrates both the application of technical and operational, information from different functional units such as human resources, sales, finance and production into a unified database and recognised the system as a business solution for many organisations to achieve desired business goals (Noor'Aini, Razilan \& Saiful Farik, 2014). ERP is absorbed into a business through several stages namely, pre-implementation, implementation, and post implementation. Typically, it starts from the normal operation of ERP and lasts until the system is replaced with a new one (Markus \& Tanis, 2000). At the post implementation phase, a business conducts its business using the ERP, and focuses on the benefits of using this system ( $\mathrm{hhu}, \mathrm{Li}$, Wang \& Chen, 2010). ERP is considered successful at the post implementation stage if it enhances the anticipated benefits through reductions of organisational cost, increased operational productivity and improved customer satisfaction levels (Sedera, Gable \& Chan, 2004). In most cases, ERP is not perfectly matched with the users' need of the system because it provides standardised processes or features to support work procedures or user tasks. Changes in users' requirements that cover all business processes are also likely to happen after the initial implementation phase due to both internal (improvement of business process and redesign projects) and external (competitors or changing government regulations) (Ahmed, Shaikh \& Sarim, 2017; Ha \& Tran 2018). ERP is embedded into an evolving task environment. If it does not fit with the business processes, the business can customise the ERP system or to adapt to the system (Sia \& Soh, 2007).

Due to the competitive environment and globalisation, SMEs have also started to implement ERP (Maldonado, 2009) as they realised that integrated systems can convert huge amounts of data into accurate information in real time. This enables them to make informed decisions to achieve their business objectives (Ahmad \& Cuenca, 2013). ERP caters for both large enterprises and SMEs to improve productivity, efficiency and overall business performance (Upadhyay, 2010). However, the rate of unsuccessful implementation of ERP is still high (He, 2004; Saeed, 2017). Although SMEs have the same requirements as large enterprises, these two enterprises face different challenges (Saini, Nigam \& Misra, 2013; Marsh et al., 2014). One of the challenges is managing change in users' requirements and maintaining their satisfaction and benefits becomes a critical issue for businesses to ensure the success of their ERP projects post implementation (Lau, Abdolali \& Yong, 2005). Peslak et al., (2008) considered the post implementation phase consists of performance and usefulness, and maintenance. The aspect of functionality, usability and adequacy are necessary in analysing, business cases and planning. The business must observe the relevance of the system and determine whether the system fits into the business process (functionality), utility and usage of system that it is providing what it is supposed to provide (usability), and whether the information system is of high quality.

\subsection{Information System Quality}

Information system quality is an important measure of IS success. Information quality is described as the output of information system whilst system quality measures the information processing system. Use is the recipient's consumption of the output of an information system and user satisfaction is the recipient's response to the use of the output of an information system. Individual impact and organisational impact are the effect of information on the behaviour of the recipient and organisational performance (DeLone \& McLean, 1992). The comprehensive review of different IS success measures provided two important contributions to the understanding of IS Success. First, it provides a structure for categorising the various IS success measures that have been used in previous studies. Secondly, it developed a model of temporal and causal interdependencies between these constructs (DeLone \& McLean, 1992; Seddon, 1997; Petter, Straub \& Rai, 2007). DeLone and McLean's IS success model (1992) became the foundation of IS success model for IS researchers. Since the model was introduced, more than 100 studies have used this model to examine IT success.

The DeLone and McLean's IS success model (1992) consists of six constructs namely, system quality, information quality, user satisfaction, use, individual impact and organisational impact as represented in Figure 1. These dimensions are not independent success measures, but rather are interdependent (DeLone \& McLean, 1992; Petter et al, 2007). Rather, the model suggests that system quality and information quality affect the system use and user satisfaction, either independently or collectively. Increased system use would affect user satisfaction either negatively or positively; user satisfaction also affects system use. System use and user satisfaction are direct precursors of individual impact. Lastly, individual impact influences organisational impact (DeLone and McLean, 1992; Livari, 2002). However, the model has received criticisms in previous studies (Seddon, 1997; Ballantine, Brignall \& Modell, 1998). These studies claimed that the DeLone and McLean's IS success model is confusing, hence reduces the value of the model since it combines both causal and process explanations of IS success. Despite the criticisms received, the model remains the most cited one in literature. 


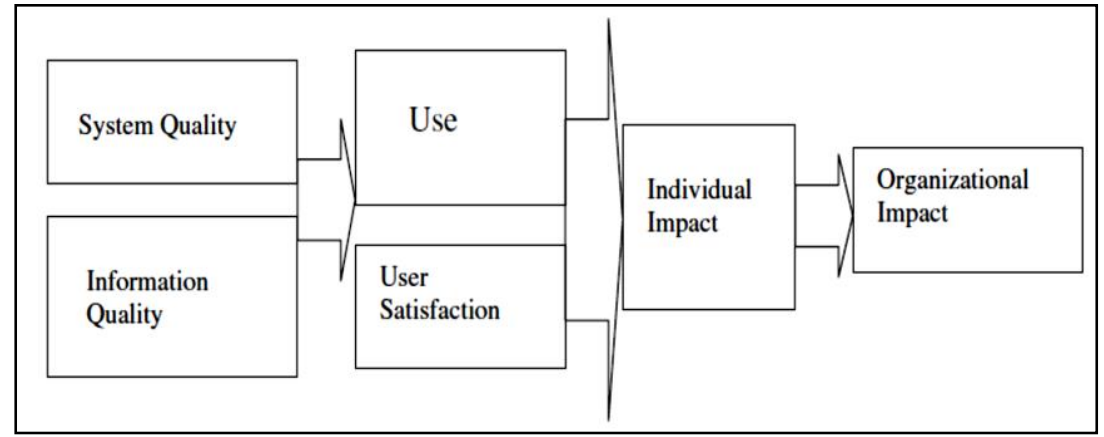

Figure 1. DeLone and McLean's model

After a decade, DeLone and McLean proposed an updated IS Success Model in 2003. An updated IS success model includes IS service quality. Figure 2 depicts DeLone and McLean's updated model with three additional dimensions namely, service quality, intention to use and net benefits. DeLone and McLean (2003) suggested service quality also measures IS success because to measure the success of a single information technology (IT), information or system quality may be a crucial factor but to measure the overall success of an IS, service quality may become the most important factor. Intention to use specifies user attitude towards the system whereas net benefits is the grouping of all the impact (individual and organisational). The impact of IT not only affects immediate users, but includes work groups, organisations, industries, consumers, and society, thus DeLone and McLean (2003) replaced the individual impact and organisational impact dimensions with "net benefits" constructs in their updated model.

Few studies have validated the IS success model. For example: Pitt, Watson and Kavan (1995) revised an IS success model which includes service quality as an additional element in the D\&M model (1992). Rai, Lang and Welker (2002) validated the two models of IS success, DeLone and McLean (1992) and Seddon (1997), with student users of an integrated information system. The study used five constructs which are system quality, information quality, perceived usefulness, user satisfaction, and use to test the models at the individual level (Rai et al., 2002). The study found that both IS success models displayed a reasonable fit to the data (Rai et al., 2002). Livari (2005) tested the D\&M model (1992) using a mandatory system with employees of a municipal corporation as subjects and used individual impacts. They found significant results for most paths of the success model.

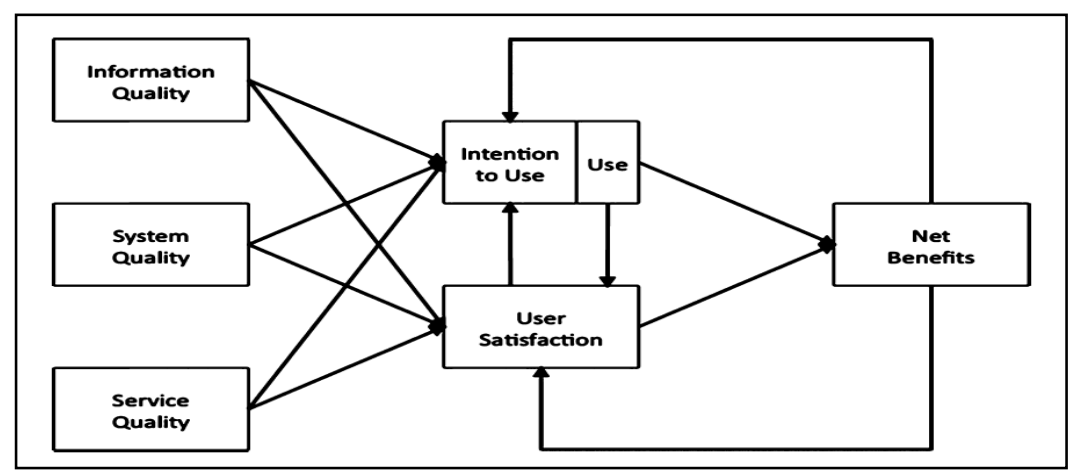

Figure 2. DeLone and McLean's updated IS success model

\section{Research Framework and Hypotheses Development}

\subsection{Research Framework}

DeLone and McLean model is an interrelated and multidimensional IS success model. This study purely adopted the Updated Delone and McLean IS Success Model (DeLone \& McLean, 2003; Habib \& Mucha 2018). However, three dimensions are excluded in this study. The intention to use and use dimensions are excluded in this study due to inappropriateness caused by biasness in evaluating ERP, since users are already obligated to use the system in their daily tasks. The SMEs put an obligation of use of ERP on their employees because they are unable to perform their assigned job without the system (Ononiwu, 2013; Noor'Aini et al, 2014). In addition, the use dimension is a 
behaviour and not an appropriate indicator of success as the utilisation of the system is normally mandatory (Seddon, 1997; Sedera et al., 2004; Holsapple et al., 2005; Hsieh \& Wang, 2007).

Besides, dimension of user satisfaction is also eliminated because this construct is more related to user attitude and user satisfaction of the system rather than performance (Noor'Aini et al., 2014). In addition, User satisfaction can be viewed as a consequence of "succeeding" IS for adopting organisations instead of a dimension of success (Seddon, 1997; Gable, Sedera \& Chan, 2008). This study focuses on the effect of ERP post implementation on the employee performance among SMEs in Malaysia. Therefore, figure 3 illustrates the conceptual framework in this study. The conceptual framework consists of 4 constructs that are categorised into two groups, one group for the three types of quality and another group for the impacts on users (i.e., employee performance). By considering the characteristics of implemented ERP systems, the framework explains how the three quality dimensions, independently and through their interactions, affect employees' performance (individual impact).

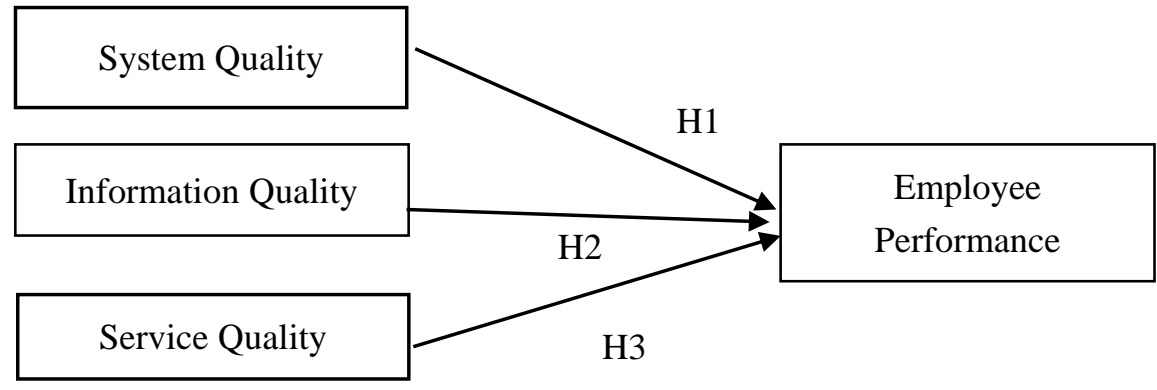

Figure 3. Research framework of this study

\subsection{Hypotheses Development}

\subsubsection{System Quality and Employees' Performance}

DeLone and McLean's (1992) IS success model assumed that there is a correlation between IS quality attributes and the benefits obtained by individuals using such systems. The IS success model indicates that when the quality attributes of an IS are perceived as high, the benefits received when individuals are using the system are also high (Holsapple et al., 2005). Therefore, system quality is one of the elements influencing the effectiveness of IT as well as user performance. Few studies have found that there is a positive relationship between system quality and "usefulness" (Seddon \& Kiew, 1994; Rai et al., 2002; Shih, 2004; Schaupp, Belanger \& Fan, 2009). Usefulness is defined by Seddon (1997, p.246) as "the degree to which the stakeholder believes that using a particular system has enhanced his or her job performance, or his or her group's or organisation's performance". Upon examining the measures used to measure this item in those studies, some relevant similarities were identified between their "usefulness" construct and the one used in this study for employees' performance which relate with individual impact construct.

Besides, Ifinedo (2007) found system quality to be positively associated with individual impact. Similarly, Hsieh and Wang (2007) also found perceived ease of use and perceived usefulness to be positively related to the benefits that individuals derive from their ERP application. However, Kositanurit, Ngwenyama \& Osei-Bryson (2006) found a significant relationship between perceived ease of use and individual performance; but they did not find any significant relationship between system reliability and the individual performance using ERP system. Therefore, based on the evidence from previous studies, this study suggests that when ERP system quality is perceived to be high, the impacts to individuals using such systems will correspondingly be high. Accordingly, this study develops the first research hypothesis:

H1: There is a positive relationship between system quality of ERP and employees' performance

\subsubsection{Information Quality and Employees' Performance}

Information quality relates to the characteristics of the output that the individuals derived from utilised ERP with respect to timeliness, relevance, availability of necessary information in real time, and understandability and accuracy. Seddon and Kiew (1994), which initiated the testing of the DeLone and McLean (1992) IS success model found that increases in quality of information would lead to more "usefulness" of an IS from an individual's perspective. Similarly, Rai et al. (2002) used both of Seddon (1997) and DeLone and McLean (1992) success models 
found that information quality is positively influenced the perceived usefulness. Ifinedo (2006) reported that information quality is positively related to Individual Impact.

Kositanurit et al. (2006) also found that there is a significant, positive relationship between informational quality of ERP system and the performance of individuals using such systems. Based on a recent study conducted by Lodhi, Abdullah and Shahzad (2016), it was suggested that performance of employees can be optimised through high quality of ERP usage. They found a positive relationship between information quality and perceived usefulness. The utilisation of ERP in a business assures the performance and growth of its employees which eventually increases the operational performance of the organisation. In spite of that, Kulkarni, Ravindran and Freeze (2006) and Ifinedo (2011) did not find a positive association between information quality and individual impact as other prior studies have done. The mixed results might be due to use of slightly different measuring items. Thus, the second hypothesis developed in this study is:

$\mathrm{H} 2$ : There is a positive relationship between information quality of ERP and employees' performance

\subsubsection{Service Quality and Employees' Performance}

Service quality relates with the overall support that an organisation received from the ERP provider comprising reliability, dependability and quality of expertise. A reliable, high-performance ERP system, together with accurate ERP information and excellent ERP support, is likely to affect user performance in performing their daily tasks. By having knowledgeable service providers (i.e., ERP vendors and consultants), it makes it easier for businesses to utilise the complex and contemporary technologies (Gefen \& Ridings, 2002; Sedera et al., 2003; Westrup \& Knight, 2000). Besides, with the provision of knowledge and expertise from external sources, users may feel encouraged to learn and attempt more of the available functions of the implemented system (Ko, Kirsch \& King, 2005; Wang \& Chen, 2006; Handa, 2018).

Lau et al. (2005) indicated that service quality complements the system quality and information quality and would significantly affect ERP post implementation success for users. Sedera et al. (2003) found that the level of employees' benefits utilising ERP is higher when there are knowledgeable and helpful ERP vendors assisting the users.

Besides, Gefen and Ridings (2002) showed that when users have greater communication with the ERP technical implementation team, their evaluations of the system tend to be more favourable compared to when having less communication. Thus, the third hypothesis is developed:

H3: There is a positive relationship between service quality of ERP and employees' performance

\section{Research Design}

\subsection{Sample Selection}

The employees who use ERP in performing their daily business tasks and who are working in the Malaysian SMEs are the sample chosen in this study. The SMEs come from a wide spectrum of industries and have implemented ERP such as SAP, Oracle and others. The employees are chosen since this study aims to examine the effect of ERP post implementation on employees' performance. Based on the list provided in the SME Annual Report 2016/17 by the SME Corporation (SME Corp), there are 920,624 SMEs in Malaysia. The scope of this study is restricted to SMEs that are located in Selangor. Based on the statistics, the highest number of SMEs is in Selangor (19.8\%), followed by Wilayah Persekutuan Kuala Lumpur (14.7\%), Johor (10.8\%), Perak (8.3\%) and other states reported with small percentage of SMEs establishments.

Since Selangor has the highest establishment of SMEs, thus the scope of this study focuses on the SMEs located in Selangor. The reasons for choosing SMEs are twofold. The first reason is that SMEs play an essential role in any economy in the world and functions as the country's economic backbone (Tan et al., 2010). Secondly, SMEs in Malaysia represent a large proportion of the total number of businesses in many industries and thus, contribute a considerable share in terms of gross domestic product (GDP). Currently, SMEs contribute 37\% to the country's GDP and is expected to exceed $40 \%$ for the year 2018 (Bernama, 2017). Therefore, the utilisation of ERP by the employees in SMEs is expected to improve efficiency of business operations.

The total population of SMEs in Selangor is 179,271 comprising of SMEs from various industries such as services, manufacturing, construction, agriculture and mining and quarrying. According to the table of sample size by Krecjie and Morgan (1970), the appropriate sample size for a population of 179,271 is 384 respondents. Thus, from the total population of SMEs, 200 SMEs were randomly selected as the sample size to get sufficient 384 responses. 


\subsection{Research Instrument}

This study employs a questionnaire-based survey as the research instrument of this study. The questionnaire consists of five sections and is structured using the Likert format with a five-point Likert scale ranging from 1 (strongly disagree) to 5 (strongly agree). At the beginning of each section, the respondents are requested to complete the questionnaire in terms of circling the numbers and scales. For Section A, the respondents are requested to complete a series of questions related to demographic profile. The questions include age, gender, marital status, job position, academic qualification, working experience and type of ERP used. Section B requests the respondents to complete a set of questions that are designed to measure the first independent variable, which is System Quality. The respondents are requested to provide their opinion about the quality of ERP performance.

Section $\mathrm{C}$ requests the respondents to complete a set of questions related to Information Quality, which is the second independent variable in this study. The respondents are requested to complete a set of questions related to quality of information produced by the ERP system to the users. Section D relates to the third independent variable namely, Service Quality. Service quality represents the quality of the support system that users received from their ERP provider. The last section, Section E concerns the effect of ERP on the individual, often assessed through increased individual's productivity, improvement in the ability of decision-making, and others.

\subsection{Variable Measurement}

\subsubsection{Independent Variables}

There are three independent variables in this study namely, system quality, information quality and service quality. Each item in the survey was based on a five-point Likert scale ranging from "strongly disagree" (1) to "strongly agree" (5) of which the respondents were requested to indicate an appropriate choice. The measurement items used for these variables were adapted from previous studies. For system quality and information quality, this study used the measurements in Sedera et al. (2004), Gable et al. (2008), and DeLone and McLean (1992). System quality is the first independent variable which is located in Section B, measured using 11 items in order to capture the performance characteristics of ERP with regards to ease of use, accuracy, reliability, efficiency, and so forth.

The second independent variable is Information Quality which comprise of 7 items that measured the characteristics of the information produced by the ERP with respect to timeliness, relevance, availability, understandability, and others. Meanwhile, the items used to measure the last variable, Service Quality were adapted from Pitt et al. (1995), Kettinger and Lee (1997), Thong, Yap and Raman (1996), and Ko, Kirsch and King (2005). This variable consists of 7 items to obtain an opinion about the quality of the support that system users received from their ERP provider.

\subsubsection{Dependent Variable}

In this study, the dependent variable is employees' performance. The item for employees' performance was adapted from previous studies by Gable et al. (2008), Sedera et al. (2003), DeLone and McLean (1992). This variable comprises of 6 items that measured the effect of ERP on employees' performance which was assessed through increased individual's productivity, improved capability of user's decision-making, and so forth. Similar to the measurement of dependent variable, the five-point Likert scale was used to measure their level of agreement or disagreement about the statement.

\subsection{Data Collection}

In this study, the questionnaire was used to gather data from the respondents. The questionnaires together with a cover letter were sent either in the form of an online survey system or personally by hand to the selected SME companies located in Selangor. The employees regardless of which department they are working for in the SMEs such as production, accounting and finance participated in the survey and their results were recorded anonymously. Regular follow up with the selected SMEs were done through phone call to ensure a high response rate.

All respondents were given two weeks from the date they received the questionnaire to complete and return the questionnaires. From the 400 set of questionnaires distributed, only 117 were returned and 283 were uncollectable due to no response. After two weeks, follow up calls were conducted to get information on the progress of the questionnaires. Therefore, the sample size of 117 respondents can be used which represents a response rate of 29 percent. The usable sample size of this study is considered acceptable as according to Sekaran and Bougie (2010), a sample size which is larger than 30 and less than 500 is appropriate for most researchers. The data collected was then analysed. 


\section{Results and Discussion}

\subsection{Demographic Information}

From the 400 set of questionnaires distributed, only 117 were returned and 283 were uncollectable due to no response. Therefore, the response rate is 29 percent. Based on 117 questionnaires, information concerning the demographics of the respondents was obtained as a reference to identify their characteristics. The demographics of the respondents in this study are age, gender, marital status, job position, academic qualification, working experience and type of ERP used. The responses received are listed in Table 1.

Table 1. Demographic information of respondents

\begin{tabular}{|c|c|c|}
\hline Demographic Profile & Frequency & Percent $\%$ \\
\hline \multicolumn{3}{|l|}{ Age: } \\
\hline Under or 25 years & 40 & 34.2 \\
\hline $26-35$ years & 47 & 40.2 \\
\hline $36-45$ years & 14 & 12.0 \\
\hline 46 - above & 16 & 13.7 \\
\hline \multicolumn{3}{|l|}{ Gender: } \\
\hline Female & 73 & 62.4 \\
\hline Male & 44 & 37.6 \\
\hline \multicolumn{3}{|l|}{ Marital Status: } \\
\hline Single & 68 & 58.1 \\
\hline Married & 49 & 41.9 \\
\hline \multicolumn{3}{|l|}{ Job Position: } \\
\hline Clerk & 18 & 15.4 \\
\hline Manager & 21 & 18.8 \\
\hline Accountant & 35 & 29.9 \\
\hline Intern & 8 & 6.8 \\
\hline Others & 34 & 29.1 \\
\hline \multicolumn{3}{|l|}{ Qualification: } \\
\hline $\mathrm{PhD}$ & 2 & 1.7 \\
\hline Master & 18 & 15.4 \\
\hline Degree & 63 & 53.8 \\
\hline Professional Qualification & 5 & 4.3 \\
\hline Diploma & 19 & 16.2 \\
\hline Others & 10 & 8.5 \\
\hline \multicolumn{3}{|l|}{ Working Experience: } \\
\hline Less than 1 year & 8 & 6.9 \\
\hline $1-5$ years & 60 & 51.3 \\
\hline $6-10$ years & 22 & 18.8 \\
\hline 11-15 years & 9 & 7.7 \\
\hline 16-20 years & 7 & 6.0 \\
\hline More than 20 years & 11 & 9.4 \\
\hline
\end{tabular}

Out of 117 respondents, majority of them are in the age between 26 to 35 years old (40.2\%) and followed by 40 respondents which are under 25 years old (34.2\%). Next, 16 of them are at the age between 46 years old and above which represents $13.7 \%$. The lowest age group is 36 to 45 years old which only comprises of 14 respondents (12\%). Majority of the respondents are female (62.4\%) meanwhile $37.6 \%$ are male. Besides that, 68 respondents are single 
$(58.1 \%)$ and the rest of them are married (41.9\%).

In terms of job position, a total of 35 respondents hold the position as accountant, followed by others (29.1\%). Next, 21 of them are managers $(18.8 \%)$, followed by 18 respondents who are working as a clerk (15.4\%) and lastly 8 respondents are interns $(6.8 \%)$. For the academic qualification, it shows that majority of them are degree holders which consist of 63 respondents (53.8\%). The second highest is diploma holders comprising 19 respondents (16.2\%), followed by master holders which consist of 18 respondents (15.3\%). Next, 10 respondents have other academic qualification, 5 respondents have professional qualification and only 2 respondents have a $\mathrm{PhD}$.

Majority of respondents which is 60 respondents $(51.3 \%$ ) have been working for 1 to 5 years. Next, 22 respondents have 6 to 10 years of working experience (18.8\%), 11 respondents have more than 20 years of working experience. Besides that, $7.7 \%$ which is 9 respondents have been working for 11 to 15 years, followed by 8 respondents who have less than 1 year of working experience (6.9\%). Lastly, 7 respondents (6\%) have experience working for 16 to 20 years. Lastly, majority of respondents mentioned that their enterprise deployed SAP and Oracle. These two types of ERP are common among employees in SMEs.

\subsection{Descriptive Statistics and Analysis}

Descriptive statistics are used to examine the trend of data to ensure the data used in this study were valid for use. The results of descriptive statistics are shown in Table 2 below which consists of mean, standard deviation and variance. The mean scores were obtained by calculating the average of respective scores. Based on the table, the result shows the mean score for information quality, system quality, service quality and employee performance are $3.869,3.995,3.829$ and 3.920 respectively. The mean score of three variables comprising system quality, information quality and service quality are above 3.500, indicating that the respondents agree that these three qualities are important for the successful post implementation of ERP. Meanwhile, the mean score of employee performance is 3.920 which is above 3.500 indicating that the respondents agree ERP influences employee performance.

Table 2. Descriptive statistic of variables

\begin{tabular}{llll}
\hline & Mean & Std. Deviation & Variance \\
\hline & Statistic & Statistic & Statistic \\
\hline System Quality & 3.869 & 0.426 & 0.181 \\
\hline Information Quality & 3.995 & 0.555 & 0.309 \\
\hline Service Quality & 3.829 & 0.515 & 0.265 \\
\hline Employee Performance & 3.920 & 0.474 & 0.225 \\
\hline
\end{tabular}

\subsection{Normality Test}

Table 3 illustrates the results of skewness and kurtosis for all variables. Hair, Black, Babin and Anderson (2010) suggest the skewness should fall between -2.0 to +2.0 whilst for the kurtosis normality range, Bryne (2010) suggests it should fall from -7.0 to +7.0 . Based on Table 3, the data in this study is assumed to be normally distributed because the value of skewness and kurtosis for all variables are between the acceptable threshold.

Table 3. Normality Test for variables

\begin{tabular}{llllll}
\hline & $\mathrm{N}$ & Skewness & & Kurtosis & \\
\hline & Statistic & Statistic & Std. Error & Statistic & Std. Error \\
\hline System Quality & 117 & -.210 & .224 & .702 & .444 \\
\hline Information Quality & 117 & -1.102 & .224 & 4.310 & .444 \\
\hline Service Quality & 117 & -.453 & .224 & 2.807 & .444 \\
\hline Employee Performance & 117 & .079 & .224 & .621 & .444 \\
\hline
\end{tabular}

\subsection{Reliability Analysis}

Table 4 presents the results of the reliability analysis. This study follows the rule of thumb for Cronbach's Alpha 
interpretation based on George and Mallery (2013). Table 4 shows that the Cronbach's alpha for system quality, service quality and employee performance are considered good whereas the information quality is excellent. Meanwhile, Cronbach alpha for overall instruments which is 0.850 is considered excellent.

Table 4. Reliability statistics

\begin{tabular}{ll}
\hline Variables & Cronbach's Alpha \\
\hline System Quality & 0.895 \\
\hline Information Quality & 0.934 \\
\hline Service Quality & 0.887 \\
\hline Employee Performance & 0.850 \\
\hline Overall & 0.957 \\
\hline
\end{tabular}

\subsection{Correlation Analysis}

The Pearson correlation coefficient is utilised to compute the strength between two continuous variables (Pallant, 2013; Hanifah, et.al 2018). The correlation coefficient value shall be within +1.0 to -1.0 , which indicates the closer the value to +1.0 , it shows a stronger relationship while 0.00 represents no relationship. The positive and negative sign indicates the relationship whether it is positively or negatively related. Hinkle, Wiersma and Jurs (2003) suggested that the rule of thumb for interpreting the size of a correlation coefficient based on the depiction in Table 5.

Table 5. Rule of thumb for interpretation the size of correlation

\begin{tabular}{ll}
\hline Size of Correlation & Interpretation \\
\hline .90 to $1.00(-.90$ to -1.00$)$ & Very high positive (negative) correlation \\
\hline .70 to $.90(-.70$ to -.90$)$ & High positive (negative) correlation \\
\hline .50 to $.70(-.50$ to -.70$)$ & Moderate positive (negative) correlation \\
\hline .30 to $.50(-.30$ to -.50$)$ & Low positive (negative) correlation \\
\hline .00 to $.30(.00$ to -.30$)$ & Little if any correlation \\
\hline
\end{tabular}

Table 6 provides a result of correlation between three independent variables which are: system quality, information quality and service quality and dependent variable: employee performance. Firstly, the system quality has a significant moderate positive relationship with information quality and service quality with $\mathrm{r}=.667, \mathrm{p}<0.001$ and $\mathrm{r}=.685, \mathrm{p}<0.001$ respectively. It shows that, when system quality increases, the information quality and service quality also would increase by 0.667 and 0.685 respectively. Next, the result shows that information quality is high positively related to service quality with a correlation of $r=735$ which is also significant at $p<0.001$. Thus, it describes that, as information quality increases, the service quality will also increase.

Besides, the result shows that system quality has a significant moderate positive correlation with employee performance at $(\mathrm{r}=.616, \mathrm{p}<0.001)$. It shows that, as system quality increases, employee performance also will increase by 0.616 . Next, information quality appears to be moderate positively related to employee performance with a coefficient of $r=.625$ which is also significant at $p<0.001$. It indicates that, as information quality increases, the employee performance will increase by 0.625 . Finally, service quality has a significant moderate positive correlation with employee performance at $(r=.695, p<0.001)$. Similarly, as service quality increases, the employee performance would also increase by 0.695 . As a conclusion, the correlation between all variables have a positive relationship and significant value at $\mathrm{p}<0.001$. 
Table 6. Pearson correlation $(\mathrm{N}=117)$

\begin{tabular}{lllll}
\hline & System Quality & Information Quality & Service Quality & Employee Performance \\
\hline System Quality & 1 & $.667^{* *}$ & $.685^{* *}$ & $.616^{* *}$ \\
\hline Information Quality & 1 & $.735^{* *}$ & $.625^{* *}$ \\
\hline Service Quality & & 1 & $.695^{* *}$ \\
\hline Employee Performance & & & 1 \\
\hline
\end{tabular}

**. Correlation is significant at the 0.01 level (2-tailed).

5.6 Multiple Regression Analysis

A Multiple linear regression analysis was used to examine the relationship between system quality, information quality and service quality with employee performance. The regression model is constructed as follows:

$$
\mathrm{EP}=\beta 0+\beta \mathrm{SQ}+\beta \mathrm{IQ}+\beta \operatorname{SerVQ}+\varepsilon
$$

Where,

$\mathrm{EP}=$ Employee Performance

$\beta 0=$ Indicates where the scope intercept

$\beta \mathrm{SQ}=$ System Quality

$\beta \mathrm{IQ}=$ Information Quality

$\beta$ SerVQ = Service Quality

$\varepsilon=$ Error

Table 7 illustrates the regression result of IS quality: system quality, information quality and service quality and employee performance. The value of $\mathrm{R}^{2}$ shows $53.2 \%$ of the variation in employee performance is explained by the variation of independent variables namely, system quality, information quality and service quality. Meanwhile, the adjusted $\mathrm{R}^{2}$ indicates $52 \%$ of the variation in employee performance can be explained by system quality, information quality and service quality, taking into account the sample size and number of independent variables. Adjusted R-square indicated how well the independent variables influence the dependent variable.

Table 7. Regression results of IS quality on employee performance

\begin{tabular}{lcccccc}
\hline Model & B & Std. Error & Beta & t. & Sig. & VIF \\
\hline (Constant) & 5.574 & 1.707 & & & & \\
\hline System Quality & .128 & .057 & .211 & 2.252 & .026 & 2.115 \\
\hline Information Quality & .127 & .074 & .173 & 1.725 & .087 & 2.443 \\
\hline Service Quality & .334 & .081 & .423 & 1.117 & .000 & 2.551 \\
\hline $\mathrm{R}^{2}$ & .532 & & & & & \\
\hline Adjusted R & & & & & & \\
\hline $\mathrm{F}$ & .520 & 42.847 & .000 & & & \\
\hline Sig.
\end{tabular}

Multicollinearity is one of the regression assumptions that should be tested before regression analysis is conducted. The cut-off points to determine the presence of multicollinearity was the VIF values which is above 10, representing that there was a possibility of multicollinearity (Pallant, 2013). Based on Table 7, the VIF values are 2.115, 2.443 and 2.551 which fall below 10 . Therefore, there are no multicollinearity issues regarding the data. In addition, the homoscedasticity test is vital as to ensure the variances are homogeneous (Field, 2013). Figure 4 shows a scatter plot that illustrates the relationship between system quality, information quality and service quality with employee performance. The results show that the scores are mostly concentrated within the centre of the variance line. Consequently, the variance is homogenous. 


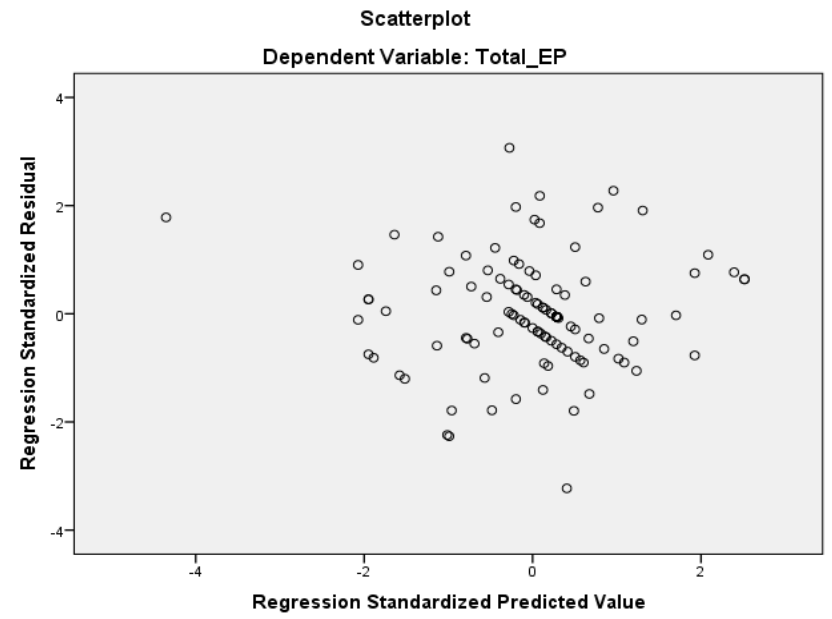

Figure 4. Scatter plot of employees' performance

The F-test was used to determine whether there is a linear relationship between the dependent and independent variables as well as the significance of the model. If the F-Statistic is significant, this indicates there is a linear relationship. The result shows that at $.10 \%$ significance level and degrees of freedom $(3,113)$, the F-Statistic is 42.847, hence HO is rejected. The results show that the linear regression exists between dependent variable with at least one independent variable. Therefore, this study concludes that there is evidence that at least one of the independent variables examined in this study affects the employee performance. Table 7 provides the result of hypotheses.

\subsubsection{System Quality and Employees' Performance}

Based on Table 8 , the beta coefficient for system quality is $.128, \mathrm{t}=2.252, \mathrm{p}=.026$ where $\mathrm{p}>.05$ proves that there is a significant positive relationship between system quality of ERP between employees' performance. The beta coefficient for system quality (.128) indicates that for every 1-point rise in the system quality, it could influence the performance of employee by .128. This finding is consistent with other prior studies supporting the existence of such a relationship (Seddon \& Kiew, 1994; Rai et al., 2002; Ifinedo, 2007; Ifinedo et al., 2010). This result shows that with high system quality, in the context of ERP would increase the performance of employees when performing their daily job. When users experience a good quality of system, with accessibility and reliability, then there is high tendency for users to extend their use of the functions and features of the system as ERP can support their work and boost their task performance (Lau et al., 2005). Besides, Ali and Younes (2013) also indicate that the quality of the ERP affects the user performance both directly and indirectly, where there is a strong direct correlation between measures of system quality and user performance. As a conclusion, system quality is one of the determinants that can influence the employee performance. Hence, hypothesis $\mathrm{H} 1$ that there is a positive relationship between system quality of ERP and employees' performance is accepted.

\subsubsection{Information Quality and Employees' Performance}

Table 8 shows the beta coefficient for information quality is $.127, t=1.725, p=.087$ where $p>.05$ proves that there is no significant positive relationship between information quality of ERP and employees' performance. The beta coefficient for information quality (.127) indicates that for every 1-point rise in the information quality of ERP, it could influence the performance of employees by .127. Unfortunately, this finding did not support a positive relationship between information quality and employee performance as other prior studies have done (DeLone \& McLean, 2003; Ifinedo, 2007; Bernroider, 2008). However, this result is in line with a previous study done by Ifinedo (2011). The peculiar nature of ERP itself has influenced this result as ERP is commonly complex in nature (Ifinedo, 2011). Many users feel frustrated when they attempt to access information and knowledge from ERP (Radding, 2000). This is because ERP is not good at providing the information needed for the purpose of long term planning and decision making as the system is only good for keeping, accessing and executing data in daily transactions but do not know how the data is to be used (Radding, 2000; Sammon, Adam \& Carton, 2003). As a conclusion, information quality of ERP does not influence the performance of employees. Hence, hypothesis $\mathrm{H} 2$ that 
there is a positive relationship between information quality of ERP and employees' performance is rejected.

\subsubsection{Service Quality and Employees’ Performance}

The result in Table 8 shows the beta coefficient for service quality is $.334, \mathrm{t}=4.117, \mathrm{p}=.000$ where $\mathrm{p}<.05$ proves that there is a significant positive relationship between service quality of ERP and employee performance. The beta coefficient for service quality (.334) indicates that for every 1-point rise in the service quality of ERP, it could affect the employee performance by .334 . This finding provides support to the positive relationship between service quality and employee performance which is in line with prior studies done by Lau et al. (2005) and Ifinedo (2011). Service quality complements the other two qualities which are system quality and service quality in ensuring the success of ERP post implementation at individual level (Lau et al., 2005). The level of benefits received by employees when using ERP is higher when the ERP providers are knowledgeable and helpful. Thus, when the quality of service provided by ERP vendors and consultants is high, the benefits to employees using the ERP will be high as well (Ifinedo, 2011). As a conclusion, service quality of ERP does influence the performance of employees. Hence, hypothesis $\mathrm{H} 2$ that there is a positive relationship between service quality of ERP and employees' performance is accepted.

Table 8. Research hypotheses and results

\begin{tabular}{lll}
\hline Hypotheses & Model & Result \\
\hline Hypothesis 1 & $\begin{array}{l}\text { There is a positive relationship between system quality of ERP and } \\
\text { employee performance }\end{array}$ & Accept \\
\hline Hypothesis 2 & $\begin{array}{l}\text { There is a positive relationship between information quality of ERP } \\
\text { and employee performance }\end{array}$ & Reject \\
\hline Hypothesis 3 & $\begin{array}{l}\text { There is a positive relationship between service quality of ERP and } \\
\text { employee performance }\end{array}$ & Accept \\
\hline
\end{tabular}

\section{Conclusion}

The effect of ERP post implementation on employee performance among SMEs in Malaysia is the theoretical foundation of this study. Specifically, this study examined the effect of three quality dimensions of the DeLone and McLean (2003) on employees' performance at ERP post implementation phase. The three quality dimensions consist of system quality, information quality and service quality. A total of 117 employees who are working in SMEs and have experience in using ERP had participated in this study by answering the questionnaires to provide their opinion whether ERP at post implementation stage would enhance their performance in performing daily tasks. This is because the expected benefits cannot be easily obtained from the ERP during the post implementation stage as the failure rates of ERP projects remain a concern.

The empirical validation of the ERP system impact model on employees' performance in a sample of 117 employees of SMEs showed that the effects of implementation of the ERP depends on the quality dimensions; system quality, information quality and service quality. The employee performance can be enhanced when the ERP is useful and easier to use in completing their job. In this study, it was found that there is a significant positive relationship between system quality of ERP and performance of employees. The results confirmed the results of previous studies such as Ifinedo (2007), and Ifinedo et al. (2011). Hence, it indicates that the high quality of ERP system plays an essential role in order to influence the employees' performance as the good functions and features of ERP are useful for them to support their work and improve their task performance. However, this study provides mixed findings on the relationship between information quality of ERP and employees' performance. This is because this study found that there is no significant positive relationship between the two variables where this finding is inconsistent with prior studies (Bernroider, 2008; DeLone \& McLean, 2003; Ifinedo, 2007; Rai et al., 2002). This suggests that when ERP is unable to provide useful information to employees, they have difficulties to access and use such information when performing their routine job.

In addition, the third relationship between service quality of ERP and performance of employees shows a positive significant relationship. It is suggested that ERP providers play a crucial role to influence the performance of employees. It is important to have ERP providers who are knowledgeable and highly experienced. Thus, when the quality of service provided by ERP vendors and consultants is high, the benefits to employees using the ERP will be 
high as well.

This study is subject to several limitations. Firstly, this study was based on a self-administered exploratory survey, where only closed-ended questions were used in the questionnaires. The respondents can answer the questionnaires based on a five point Likert scale. Hence, this restricted this research to ask open-ended questions, which could provide a better understanding of the effect of ERP on employee performance. Besides that, the employees may want to describe and discuss in detail about any issues related with the system when conducting an interview session with them as direct feedback can be obtained from them. Another limitation of this research is the choice not to use control variables, such as type of industry or size of organisation which could potentially influence the dependent variables (employee performance). This study is conducted regardless of industry type (manufacturing, services or others) and organisation size (small or medium enterprise). Besides, there are limited literature reviews available especially those related with ERP post implementation stage and the effect of ERP on employee performance among SMEs. This is because many prior studies are more focused on the effect of ERP at organisational level and the findings were from a large organisation perspective, and less on SMEs point of view. This study is conducted regardless of the industry type (manufacturing, services or others) and organisation size (small or medium enterprise). Different findings may emerge if the study investigated the effect of ERP based on specific industries such as manufacturing or services or agricultural and specific size of organisation which are small or medium enterprises. Thus, more research should be performed to provide more findings on this specific area. Besides, this study found that there is no positive relationship between information quality and employee performance. This finding contradicted the studies done by Bernroider, (2008), DeLone \& McLean (2003), and Ifinedo (2007). Therefore, the relationship between the two dimensions or measures which is different with the concept of IS success evaluation in the existing IS literature, hence requires further investigation in the future.

In summary, the result of this study can be useful for the implementation and management of ERP to evaluate the effect of ERP post implementation on employees' performance. It is important to consider the effectiveness of ERP based on the quality dimensions during ERP post implementation stage to ensure the system matches their job requirement and is able to support their work procedures and tasks. Therefore, the quality of ERP, quality of information and quality of service provided by ERP providers are important elements to influence the employees' performance.

\section{Acknowledgment}

We wish to thank the Institute of Quality and Knowledge Advancement and the Institute of Research Management and Innovation for their support in funding this project.

\section{References}

Ahmad, M. M., \& Cuenca, R. P. (2013). Critical success factors for ERP implementation in SMEs. Robotics and Computer-Integrated Manufacturing, 29(3), 104-111. https://doi.org/10.1016/j.rcim.2012.04.019

Ahmed, N., Shaikh, A. A., \& Sarim, M. (2017). Critical success factors plays a vital role in ERP implementation in developing countries: An exploratory study in Pakistan. International Journal of Advanced Computer Science and Applications, 8(10), 21-29. https://doi.org/10.14569/IJACSA.2017.081004

Ali, B. M., \& Younes, B. (2013). The impact of ERP system on user performance. Journal of Theoretical \& Applied Information Technology, 52(3), 325-242.

Armstrong, H., \& Baron, A. (2002 ). Performance Management. London: Institute of Personnel and Development.

Bailey, J., \& Pearson, S. (1983). Development of a tool for measuring and analyzing computer user satisfaction. Management Science, 29(5), 530-545. https://doi.org/10.1287/mnsc.29.5.530

Ballantine, J., Brignall, S., \& Modell, S. (1998). Performance measurement and management in public health services: A comparison of UK and Swedish practice. Management Accounting Research, 9, 71-94. https://doi.org/10.1006/mare.1997.0067

Bernama. (2017, July 13). Malaysia's SME GDP contribution to exceed 40\%. The Star online. Retrieved from https://www.thestar.com.my/business/business-news/2017/07/13/malaysias-sme-gdp-contribution-to-exceed-40 pct

Bernroider, E. W. (2008). IT governance for enterprise resource planning supported by the DeLone-McLean model of information systems success. Information \& Management, 45(5), 257-269. https://doi.org/10.1016/j.im.2007.11.004 
Botta-Genoulaz, V., \& Millet, R. A. (2006). An investigation into the use of ERP systems in the service sector. International Journal of Production Economics, 99(1), 202-221. https://doi.org/10.1016/j.ijpe.2004.12.015

Brehm, L., Heinzl, A., \& Markus, M. L. (2001). Tailoring ERP systems: a spectrum of choices and their implications, Proceedings of the 34th Annual Hawaii International Conference on System Sciences (pp. 1-9).

Caruso, D. (2003). The world class challenge: six critical issues midmarket manufacturers must address. SVP Research, AMR Research Inc, 1-9

DeLone, W. H., \& McLean, E. R. (1992). Information systems success: The quest for the dependable variable. Information Systems Research, 3(1), 60-95. https://doi.org/10.1287/isre.3.1.60

DeLone, W. H., \& McLean, E. R. (2003). The DeLone and McLean model of information systems success: a ten-year update. Journal of Management Information Systems, 19(4), 9-30. https://doi.org/10.1080/07421222.2003.11045748

ERP Report 2015. (2015). A Panorama. Consulting Solutions Research Report, Denver, USA. Retrieved from http://panorama-consulting. com/resource-center/2015-erp-report/

Field, A. (2013). Discovering statistics using IBM SPSS statistics. Sage.

Ford, G., \& Gelderblom, H. (2003). The effects of culture on performance achieved through the use of human computer interaction. Proceedings of the 2003 annual research conference of the South African institute of computer scientists and information technologists on Enablement through technology (pp. 218-230).

Gable, G., Sedera, D., \& Chan, T. (2008). Reconceptualizing information system success: The IS-impact measurement model. Journal of the Association for Information Systems, 9(7), 377-408 https://doi.org/10.17705/1jais.00164

Gefen, D., \& Ridings, C. M. (2002). Implementation team responsiveness and user evaluation of customer relation management: A quasi-experimental design study of social exchange theory. Journal of Management Information Systems, 19(1), 47-69. https://doi.org/10.1080/07421222.2002.11045717

George, D., \& Mallery, P. (2003). SPSS for Windows step by step: A simple guide and reference. 11.0 update (4th ed.), p. 231. Boston: Allyn \& Bacon.

Gumusgul, O. (2018). Comparison of Time Management Perception of Students Studying at Department of Physical Education and Sports Teaching and Program in Primary School Education. Asian Journal of Education and Training, 4(3), 224-227. https://doi.org/10.20448/journal.522.2018.43.224.227

Gyebi, F., Owusu, M., \& Etroo, J. K. (2013). Foreign Direct Investment and Gross Domestic Product in Ghana. International Journal of Academic Research in Accounting, Finance and Management Services, 3(3), 256-65. https://doi.org/10.6007/IJARAFMS/v3-i3/153

Ha, T. P. T., \& Tran, M. D. (2018). Review of Impacts of Leadership Competence of Project Managers on Construction Project Success. International Journal of Emerging Trends in Social Sciences, 4(1), 15-25. https://doi.org/10.20448/2001.41.15.25

Habib, A., \& Mucha Sr, M. (2018). The Lifecycle and Effective Communication of CSR to the Stakeholder and the Public. International Journal of Economics, Business and Management Studies, 5(1), 1-8. https://doi.org/10.20448/802.51.1.8

Hair, J. F., Black, W. C., Babin, B. J., \& Anderson, R. E. (2010). Multivariate Data Analysis (7th ed.). Prentice Hall, Upper Saddle River, New Jersey.

Handa, R. (2018). Does Corporate Governance Affect Financial Performance: A Study of Select Indian Banks. Asian Economic and Financial Review, 8(4), 478-486.

Hanifah, M., Mohmadisa, H., Yazid, S., Nasir, N., \& Saiyidatina Balkhis, N. (2018). Developing Low Carbon Schools Model through Students Involvement in Sustainability Activities. International Journal of Asian Social Science, 8(8), 591-602. https://doi.org/10.18488/journal.1.2018.88.591.602

He, X. (2004). The ERP challenge in China: A resource-based perspective. Information Systems Journal, 14(2), 153-167. https://doi.org/10.1111/j.1365-2575.2004.00168.x

Hinkle, D. E., Wiersma, W., \& Jurs, S. G. (2003). Applied statistics for the behavioral sciences (5th ed.). Boston, MA: Houghton Mifflin Company. 
Hodgkinson, A. (1999). Productivity Measurement and Enterprise Bargaining - The Local Government Perspective. The International Journal of Public Sector Management, 12, 6. https://doi.org/10.1108/09513559910301342

Holsapple, C. W., Wang, Y.-M., \& Wu, J.-H. (2005). Empirically testing user characteristics and fitness factors in ERP success. International Journal of Human-Computer Interaction, 19(3), 323-342. https://doi.org/10.1207/s15327590ijhc1903_3

Hsieh, J., \& Wang, W. (2007). Explaining employees' extended use of complex information systems. European Journal Information System, 16(3), 216-227. https://doi.org/10.1057/palgrave.ejis.3000663

Idrus, R., \& Shahawai, S. S. (2009). Research Methodology for Assessing Malaysian SMEs perspective on ERP. Paper presented at the Modelling \& Simulation, 2009. AMS'09. Third Asia International Conference on Modelling \& Simulation (pp.407-412). https://doi.org/10.1109/AMS.2009.122

Ifinedo, P. (2007). Investigating the relationships among ERP systems success dimensions: A structural equation. Issues in Information Systems, 8(2), 399-405.

Ifinedo, P. (2011). Examining the influences of external expertise and in-house computer/IT knowledge on ERP system success. Journal of Systems and Software, 84(12), 2065-2078. https://doi.org/10.1016/j.jss.2011.05.017

Ko, D., Kirsch, J. L., \& King, W. R. (2005). Antecedents of knowledge transfer from consultants to clients in enterprise system implementations. MIS Quarterly, 29(1), 59-85. https://doi.org/10.2307/25148668

Kositanurit, B., Ngwenyama, O., \& Osei-Bryson, K. M. (2006). An exploration of factors that impact individual performance in an ERP environment: an analysis using multiple analytical techniques. European Journal of Information Systems, 15(6), 556-568. https://doi.org/10.1057/palgrave.ejis.3000654

Krejcie, R. V., \& Morgan, D. W. (1970). Determining sample size for research activities. Educational \& Psychological Measurement, 30, 607-610. https://doi.org/10.1177/001316447003000308

Kulkarni, U. R., Ravindran, S., \& Freeze, R. (2006). A knowledge management success model: Theoretical development and empirical validation. Journal of Management Information Systems, 23(3), 309-347. https://doi.org/10.2753/MIS0742-1222230311

Lau, P. M., Abdolali, K. A., \& Yong, D. (2005). Service quality: A study of the luxury hotels in Malaysia. Journal of American Academy of Business, 7, 46-55.

Lee, J. (2017, September 25). Recognising Growth of SMEs. The Star Online. Retrieved October 19, 2018, from https://www.thestar.com.my/business/smebiz/2017/09/25/recognising-growth-of-smes/

Livari, J. (2002). An empirical test of the DeLone-mclean model of information system success. ACM New York, 2(36), 8-27. https://doi.org/10.1145/1066149.1066152

Livari, J. (2005). An empirical test of the DeLone-McLean model of information system success. ACM SIGMIS Database: the DATABASE for Advances in Information Systems, 36(2), 8-27. https://doi.org/10.1145/1066149.1066152

Lodhi, R. N., Abdullah, M., \& Shahzad A. (2016). An empirical investigation of the effectiveness of ERP quality: Evidence from corporate sector of Pakistan. Journal of Quality and Technology Management, 12(2), 71-88.

Maldonado, M. (2009). Factors impacting the success of ERP implementations in small and medium enterprises: An empirical assessment from Latin America. Proceedings of the Fourteenth Americas Conference on Information Systems.

Noor'Aini, I., Razilan, A. K., \& Saiful Farik, M. Y., (2014). An empirical study on effectiveness on ERP system. Australian Journal of Basic and Applied Science, 8(23), 144-150.

Ononiwu, C. G. (2013). A delphi examination of inhibitors of the effective use of process industry enterprise resource planning (ERP) systems: A case study of New Zealand's process industry. Electronic Journal of Information Systems Evaluation, 16(2), 116-133.

Pallant, J. (2013). SPSS survival manual: A step by step guide to data analysis using IBM SPSS (4th ed.). Crows Nest, NSW: Allen \& Unwin

Petter, D., Straub, D., \& Rai, A. (2007). Specifying formative constructs in Information Systems research. MIS Quarterly, 31(4). 623-656. https://doi.org/10.2307/25148814

Pinedo-Cuenca, R., Shaw, T., Ahmad, M., \& Abbas, A. (2004). Adoption of ERP systems in SMEs. Proceedings of 
Conference on Flexible Automation and Intelligent Manufacturing (FAIM), 1240-1247.

Pitt, L. F., Watson, R. T., \& Kavan, C. B. (1995). Service quality: A measure of information systems effectiveness. MIS Quarterly, 19(2), 173-188. https://doi.org/10.2307/249687

Radding, A. (2000). Knowledge management appears on ERP radar. Datamation. Retrieved from http://itmanagement.earthweb.com

Rai, A., Lang, S. S., \& Welker, R. B. (2002). Assessing the validity of IS success models: An empirical test and theoretical analysis. Information Systems Research, 13(1), 50-69. https://doi.org/10.1287/isre.13.1.50.96

Rajan, C. A., \& Baral, R. (2015). Adoption of ERP system: An empirical study of factors influencing the usage of ERP and its impact on end user. IIMB Management Review, 27(2), 105-117.

Sahran, S., Goni, F. A., \& Mukhtar, M. (2010). ERP implementation challenges in small and medium enterprise: A framework and case study. Advanced Materials Research, 139, 1636-1639.

Sammon, D., Adam, F., \& Carton, F. (2003). Benefit realisation through ERP: The reemergence of data warehousing. The Electronic Journal of Information Systems Evaluation, 6(2), 155-164.

Schaupp, L. C., Belanger, F., \& Fan, W. (2009). Examining the success of websites beyond e-commerce: An extension of the IS success model. Journal of Computer Information Systems, 49(4), 42-52.

Seddon, P. B. (1997). A re-specification and extension of the DeLone and McLean model of IS success. Information Systems Research, 18(3), 240-253. https://doi.org/10.1287/isre.8.3.240

Seddon, P. B., \& Kiew, M.-Y. (1994). A partial test and development of the DeLone and McLean model of IS success. Proceedings of the international conference on information systems, Vancouver, Canada.

Sedera, D., Gable, G., \& Chan, T. (2004). A factor and structural equation analysis of the enterprise systems success measurement model. Proceedings of the $25^{\text {th }}$ international conference on information systems, Washington, DC, USA.

Sekaran, U., \& Bougie, R. (2010). Research Methods for Business: A Skill Building Approach (5th ed.). West Sussex, UK: John Wiley \& Sons Ltd.

Shih, H. P. (2004). Extended technology acceptance model of internet utilization behavior. Information \& Management, 4l(6), 719-729. https://doi.org/10.1016/j.im.2003.08.009

Sia, S. K., \& Soh, C. (2007). An assessment of package-organisation misalignment: institutional and ontological structures. European Journal of Information Systems, 16(5), 568-583.

Sonnentag, S., \& Frese, M. (2003). Performance concepts and performance theory. Psychological Management of Individual Performance, 1-26. https://doi.org/10.1002/0470013419.ch1

Spool, J., Scanlon, S., Schroeder, W., Snyder, C., \& Deangelo, T. (1999). Web Site Usability: A Designers Guide. San Francisco CA: Morgan Kaufman Publishing.

Sun, A. Y. T., Yazdani, A., \& Overend, J. D. (2005). Achievement assessment for enterprise resource planning (ERP) system implementations based on critical success factors (CSFs). International Journal of Production Economics, 98(2), 189-203. https://doi.org/10.1016/j.ijpe.2004.05.013

Thong, J. Y. L., Yap, C., \& Raman, K. S. (1996). Top management support, external expertise and information systems implementation in small businesses. Information Systems Research, 7(2), 248-267.

Wang, E. T. G., \& Chen, J. H. F. (2006). Effects of internal support and consulting quality on the consulting process and ERP system quality. Decision Support Systems, 42, 1029-1041.

Wang, E. T. G., Shih, S.-P., Jiang, J. J., \& Klein, G. (2008). The consistency among facilitating factors and ERP implementation success: A holistic view of fit. Journal of Systems and Software, 81(8), 1609-1621.

Westrup, C., \& Knight, F. (2000). Consultants and enterprise resource planning (ERP) systems. Proceedings of the European conference on information systems, Vienna, Austria.

Yu, C.-S. (2005). Causes influencing the effectiveness of the post-implementation ERP system. Industrial Management \& Data Systems, 105(1), 115-132. https://doi.org/10.1108/02635570510575225

Zhu, Y., Li, Y., Wang, W., \& Chen, J. (2010). What leads to post-implementation success of ERP? An empirical study of the Chinese retail industry. International Journal of Information Management, 30(3), 265-276. 